\title{
GASEOUS AND THERMAL ANALYSIS OF WINTER GARDEN USED FOR AIR REGENERATION THROUGHOUT OFFICE BUILDINGS
}

\author{
Andrey RYMAROV ${ }^{1}$, Natalia PARFENTEVA ${ }^{1}$, Kęstutis VALANČIUS² ${ }^{*}$, \\ Sabina PAULAUSKAITÉ2 ${ }^{2}$, Violeta MISEVIČIŪTĖं2 \\ ${ }^{1}$ Moscow State University of Civil Engineering, 26 Yaroslavskoye Shosse, Moscow, Russia \\ ${ }^{2}$ Vilnius Gediminas Technical University, Sauletekio al. 11, Vilnius, Lithuania
}

Received 16 September 2017; accepted 26 February 2018

\begin{abstract}
Ecological problems are inherent in the issue of air quality in the buildings. The main goal thus becomes the creation of indoor clime, where concentration of the detrimental impurities, such as carbon dioxide, would not exceed established norms. Thus, it is proposed to develop an alternative system of ventilation, which would ensure necessary indoor climate without outside air use. In order to decrease the levels of it inside the buildings, it is suggested to use a winter garden with much greenery, so that the air would be regenerated since the carbon dioxide would be absorbed and oxygen would be evolved. The current work reveals the study results of thermal, air and gas conditions in a winter garden upon the office building. The proposed methodology based on the ANSYS-CFX software, ensures a successful calculation of heating and aerial regimes within buildings that might differ in accordance with various engineering practices.
\end{abstract}

Keywords: air regeneration, ANSYS-CFX, carbon dioxide, indoor air quality, ventilation, winter garden.

\section{Introduction}

The ecological problems have currently gone top especially in relation with the deterioration in quality of the indoor climate (Kvashnin, Gurin 2008; Germanova, Kernozhitskaya 2014; Lott et al. 2017). The issue of air quality in buildings are becoming more and more urgent. The main goal thus becomes the creation of indoor climate, in which the concentration of the detrimental impurities, such as carbon dioxide, would not exceed established norms. That is why ventilation systems are being developed and enhanced (Sinitsyn, Shurshakova 2015). Nonetheless, improvements of the air quality at the expense of mechanical ventilation, i.e. the process whereby the air exchange needed between the building and outdoor area is not necessarily effective (Steinemann et al. 2017), since there is a possibility of the air pollution coming inside the building.

Thus, it is proposed to develop an alternative system of ventilation, which would ensure necessary indoor climate without outside air use (Rymarov, Savichev 2013). The most noxious component of the office air is carbon dioxide, which is commonly referred to as an indicator of air pollution (Allen et al. 2016).

Too high levels of carbon dioxide negatively affects the health and productivity of a person that work in the office
(Leivo et al. 2016; Chenari et al. 2016; Wargocki, Wyon 2017). Analysing alternative ventilation systems $\mathrm{CO}_{2}$ capture devices can be applied for energy saving in the building. Air can be treated by diluting polluted air with fresh air, and capturing air pollutants by specialized filters. In extreme climates, the latter method is more preferable in order to save energy. Many studies describe filters that can capture most pollutants such as VOCs, dust and odors (Hyttinen et al. 2007; Gallego et al. 2013), unfortunately these cannot reduce $\mathrm{CO}_{2}$ concentration (Kim et al. 2015). Greenery systems could be suggested as an up-and-coming solution for increase of buildings energy efficiency. The latter systems can be used not only to increase the energy efficiency of a building, but also to influence the indoor climate and air quality in the building (Raji et al. 2015).

In order to decrease the levels of carbon dioxide inside the buildings, it is suggested to use a "winter garden" with much greenery, so that the air would be regenerated since the carbon dioxide would be absorbed and oxygen would be evolved (Enteria et al. 2016). The current work reveals the study results of thermal, air and gas conditions in a winter garden upon the office building.

${ }^{*}$ Corresponding author. E-mail: kestutis.valancius@vgtu.lt 


\section{Methodology}

In the work conducted a solution for such a crosscutting issue as the regeneration capacity of a winter garden, which is combined with the premises of the administrative building via air in order to decrease the concentration of carbon dioxide and, accordingly, to increase the oxygen saturation, was offered. Within the current framework, the concept of a winter garden could be defined as a building within or without other premises, wherein plants regenerate air by trapping $\mathrm{CO}_{2}$ and evolving oxygen (Toledo et al. 2016). At the same time, the premises may be connected with the "winter garden" by recirculating ventilation system (Alonso et al. 2015). This building may serve as capacity filled with plants, which are capable of an active photosynthesis (Paevere et al. 2008). The capacity of the greenery needed for the regeneration of air gas composition within the administrative premises defines the required capacity and area of the winter garden.

Figure 1 schematically presents the abilities of the winter garden ventilation system to restore the gas composition of air within the administrative premises:

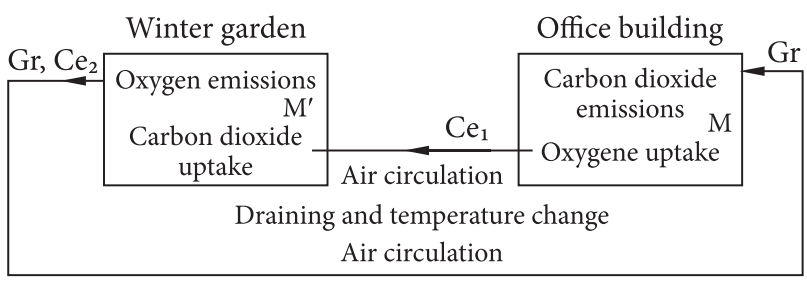

Figure 1. Organization of the ventilation system with the restoration of the gas composition of the air. Hence, $\mathrm{M}^{\prime}$ is the power source of harmful emissions $(\mathrm{kg} / \mathrm{h})$; $\mathrm{M}$ - the regenerative power to absorb $\mathrm{CO}_{2}$ by plant surfaces $\left(\mathrm{kg} /\left(\mathrm{m}^{2} \times \mathrm{h}\right)\right) ; \mathrm{Gr}-$ the amount of air subject to restoration $(\mathrm{kg} / \mathrm{h}) ; \mathrm{C}_{\mathrm{e} 1}-$ mass concentration of $\mathrm{CO}_{2}$ in the air taken from the "winter garden" $\left(\mathrm{kg} / \mathrm{m}^{3}\right) ; \mathrm{C}_{\mathrm{e} 2}-$ mass concentration of $\mathrm{CO}_{2}$ in the air of office premises that is fanned to the "winter garden" $\left(\mathrm{kg} / \mathrm{m}^{3}\right)$
In order to organize the air recirculation from the office premises to the winter garden buildings and back, the required specifications of the microclimate (Toledo et al. 2016) within both types of premises should be created.

It has been assumed that the indoor air treatment takes place via winter garden. The polluted airflows with high level of carbon dioxide move inside winter garden, where they are transmitted through the greenery, thus the air, purified by photosynthesis, is transported in the office building (Figure 1).

Along with its plants, the winter garden is designed for the year-round implementation within regenerative system of the recirculation air, which flows from the office premises to the winter garden and back. The airflow with an increased $\mathrm{CO}_{2}$ and a decreased $\mathrm{O}_{2}$ mass concentration passes through the leaves and changes the air composition. Thus, the concentration of $\mathrm{CO}_{2}$ is going down, whereas the concentration of $\mathrm{O}_{2}$ is going up. The capacity of the winter garden should be filled with biomass, which is capable of photosynthesis, wherein the regenerative processes of air composition take place. In order to decrease capital and operating costs and to increase productivity of the premises in terms of the regenerative abilities of the increasing $\mathrm{CO}_{2}$ concentrations, the highest possible filling of the garden's capacity with plants is required.

At its height, the building of the winter garden is laid out in three zones (Figure 2) with the corresponding $\mathrm{CO}_{2}$ and $\mathrm{O}_{2}$ gas modes. The first zone includes all the space from air supply to the place, where the air gets in touch with the surface of plants, wherein the concentration of $\mathrm{CO}_{2}$ is constant and is equal to concentration of the air, coming from the office premises. The second zone, which is filled with the deciduous coverage and is commonly referred to as the "working area", enables the air quality to be renewed its gas composition, i.e. decreases the concentration of $\mathrm{CO}_{2}$ and increases the levels of $\mathrm{O}_{2}$ in the air. The third zone includes the space between the bottom line of the deciduous coverage and the soil, wherein the

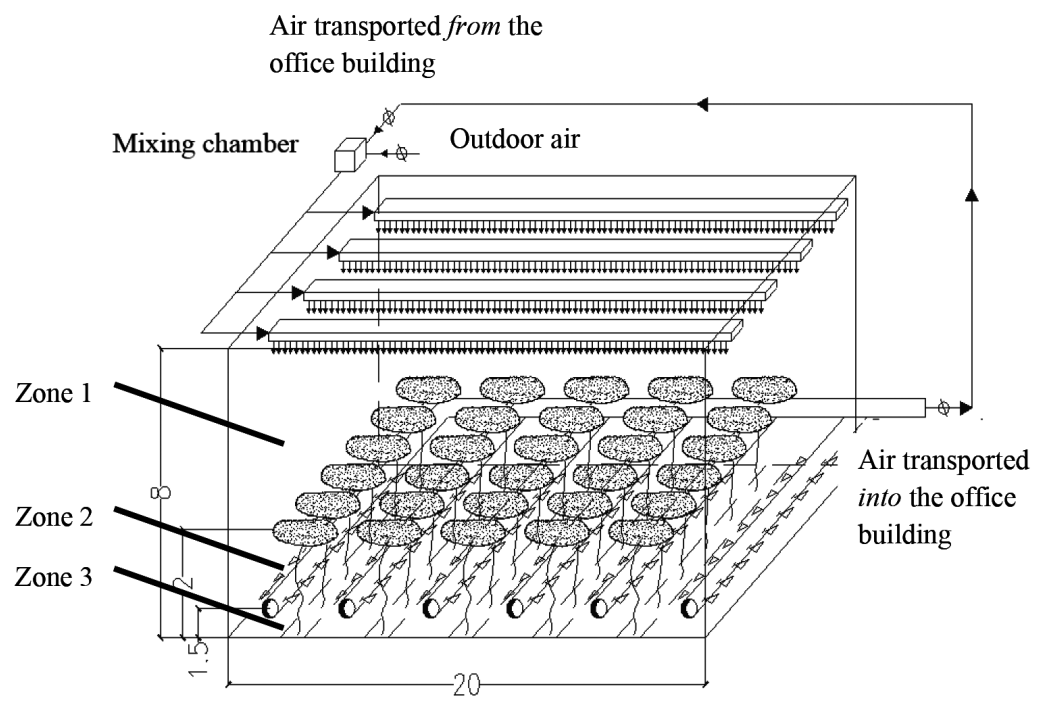

Figure 2 . The scheme of air recirculation for a winter garden (size $20 \times 10 \times 8 \mathrm{~m}$ ) 
concentration of $\mathrm{CO}_{2}$ in the air is reduced to concentration that belongs to the composition of clean air, which is infiltrated with oxygen. The scheme of the following division according to its height is presented in Figure 2.

It should be mentioned that the given task is quite complex since the issues of defining gas, thermal and air conditions must be solved. Apparently, the solution of this problem as well as the modelling of processes implied certain approximations.

Modelling and process-related calculations were conducted via ANSYS-CFX software.

The flow of air with heat-and-mass transfer under the initial conditions was modelled, given the physiology of the plant life. Meantime, the hydrodynamic equations were solved. The parameters of the flows of gases and air masses were calculated by means of numerical solution, which consists of the Navier-Stokes equations and continuity. Current paper provides model equations that are entered in the system of equations of the flows of air and gas with heat transfer.

Mathematical modelling of the heat exchange inside winter garden building allowed making the following assumptions:

- A stationary, two-dimensional field is under the investigation;

- The flow of air inside winter garden building is considered laminar, non-isothermal;

- The heat exchange occurs due to both forced and natural convection.

The non-isothermal airflow could be described by the Navier-Stoke equation system, at Boussinesq approximation (Gershuni, Zhuchovickiy 1989).

Under the variables of the current function $\psi$ and vorticity $\omega$, the system of equations appears as (1-3):

$$
\frac{\partial(U \omega)}{\partial x}+\frac{\partial(V \omega)}{\partial y}=\frac{\partial^{2} \omega}{\partial x^{2}}+\frac{\partial^{2} \omega}{\partial y^{2}}+G r \frac{\partial \theta}{\partial x},
$$

where: $U, V$ - velocity projection on the $\mathrm{x}$ and y axis; $\omega-$ stream function; $\psi$ - vorticity; $\theta$ - temperature; $G r$ - Grashof number.

Equation (1) describes the motion of air masses of the winter garden height. Equation (2) describes the exchange process between heating surfaces and air of a winter garden:

$$
\frac{\partial(U \theta)}{\partial x}+\frac{\partial(V \theta)}{\partial y}=\frac{1}{\operatorname{Pr}}\left(\frac{\partial^{2} \theta}{\partial x^{2}}+\frac{\partial^{2} \theta}{\partial y^{2}}\right),
$$

where: Pr - Prandtl number.

Equation (3) is an equation of continuity:

$$
\frac{\partial^{2} \psi}{\partial x^{2}}+\frac{\partial^{2} \psi}{\partial y^{2}}+\varpi=0
$$

Parameters used for expressions (1-3) are calculated following the formulas (4-9):

$$
G r=\frac{\beta g H^{3}}{v^{2}}\left(t_{1}-t_{3}\right)
$$

where: $\beta, v, k$-volume expansion coefficients of the kinematic viscosity and the thermal air conductivity respectively; $g$ - gravitational acceleration; $H, t_{1}-t_{3}$ - length and air temperature on the boundaries 1 and 3 respectively.

$$
\operatorname{Pr}=\frac{v}{k}
$$

where: $k$ - the thermal air conductivity.

Temperature $(\theta)$, velocity projection on the $x(U)$ and $y(V)$ axis respectively and stream function $(\omega)$ are found according equations (6-9):

$$
\begin{aligned}
& \theta=\frac{\left(t-t_{3}\right)}{\left(t_{1}-t_{3}\right)} ; \\
& U=\frac{\partial \psi}{\partial y} ; \\
& V=-\frac{\partial \psi}{\partial x} ; \\
& \omega=\frac{\partial V}{\partial x}-\frac{\partial U}{\partial y} .
\end{aligned}
$$

The system has been recorded in the dimensionless form, where $H, v, t_{1}-t_{3}$ represent the length, velocity and temperature values respectively, whereas other designations have been entered as follows: $\theta$ - temperature; $\mathrm{Gr}$ Grashof number; $\operatorname{Pr}$ - Prandtl number; $U, V$ - velocity projection on the $x$ and $y$ axis; $\psi$ - vorticity; $\omega$ - stream function; $t_{1}, t_{3}$ - air temperature on the boundaries 1 and 3 respectively; $\beta, v, k$-volume expansion coefficients of the kinematic viscosity and the thermal air conductivity respectively.

Two modes of the airflow for a winter garden were considered throughout the height. The first mode, along with the natural convection titled "thermal regime", corresponds to Figure 3(a), whereas the second mode with the forced convection titled "gas regime" corresponds to Figure 3(b), respectively. The differences between these two regimes are the calculated schemes of mathematic models and initial/boundary conditions.

Figure 3(a) provides a closed-rated operating region without air intake or venting but with the boundaries viewed as claddings. Mode 2 is seen as unclosed-rated operating system (Figure 3(b)) having a permanent air intake/outtake and the boundaries also viewed as claddings.

Boundary conditions for the first mode are represented as follows: on the plane of soil surface G1 $t=t_{1}$; on the plane of the claddings $\mathrm{G} 2: \frac{\partial t}{\partial n}=-q_{2}$ (where minus shows the distortion between heat flow and OX axis); on the upper plane of the winter garden G3: $t=t_{3}$; on the G4: $\frac{\partial t}{\partial n}=q_{4}$ : plane; on the heating device surface G5: $t=t_{5}$.

The boundary conditions for the second regime are represented as follows: on the plane of soil surface G1: 
a)

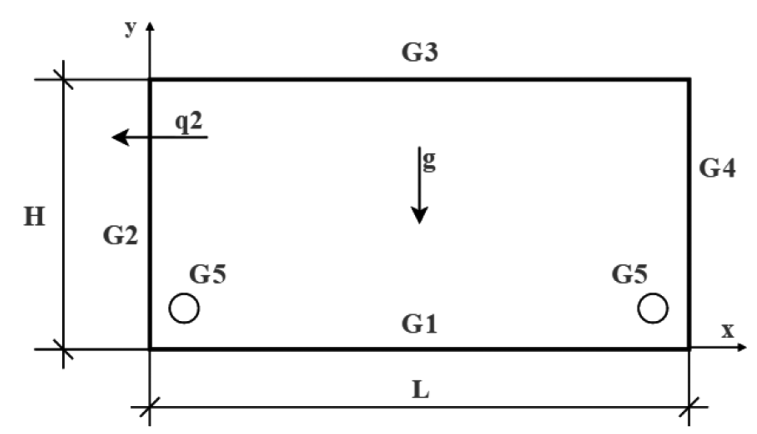

b)

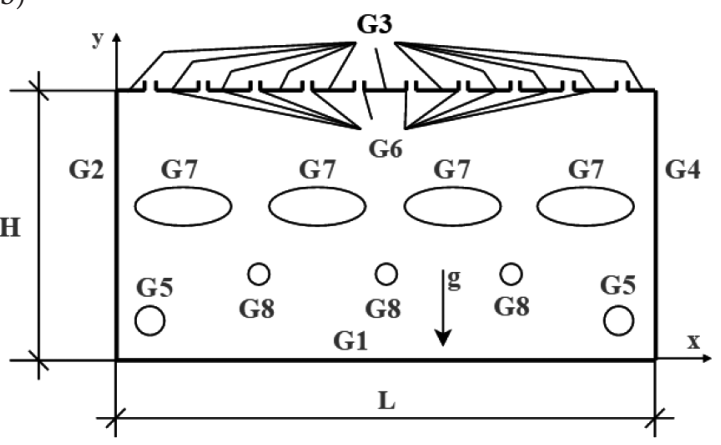

Figure 3. Closed-rated (a) and unclosed-rated (b) operating zones for air flow calculation

$t=t_{1}$; on the surface of claddings $\mathrm{G} 2: \frac{\partial t}{\partial n}=-q_{2}$ (where minus shows the distortion between heat flow and the direction of OX axis); on the upper plane G3: $t=t_{3}$; on the G4: $\frac{\partial t}{\partial n}=q_{4}$ plane (axis of symmetry; interior volume); and, finally, on the surface of heating devices G5: $t=t_{5}$. The planes G6, G8 represent the boundaries between airdistributing and air-venting channels. Boundary of the G6 models the ventilation channel, through which the air that is taken from the office buildings with high concentration of carbon dioxide gets into the winter garden building. Boundary of the G7 models green vegetative cover, which absorbs carbon dioxide, whereas boundary of the G8 models the ventilation channel, which serves to regenerate the air and deliver it back to the office buildings.

Regime 2 requires the following boundary conditions. For the boundary G6, the air output is known (Eq. (4)):

$$
\frac{\partial \psi}{\partial n}=G 6
$$

On the boundary G7 (Eq. (5)):

$$
\frac{\partial \psi}{\partial n}=-G 7
$$

On the boundary G8 (Eq. (6)):

$$
\frac{\partial \psi}{\partial n}=-G 8 \text {. }
$$

Hence, the minus in the last expression (6) shows that the airflow transgresses the operating region. The modelling of recirculating regenerating ventilation has been based upon winter garden building with specific geometrical dimensions $(20 \times 10 \times 8) \mathrm{m}$ and operation mode of engineering systems. Furthermore, the calculations are set by thermal behaviour of the indoor air, temperatures of surface and air output, thermotechnical characteristics of the claddings as well as the area and the regenerative power of the greenery surfaces. The air output from the office building to the capacity of a winter garden with higher concentration of $\mathrm{CO}_{2}$ has the initial velocity of $0.20 \mathrm{~m} / \mathrm{sec}$, the $\mathrm{CO}_{2}$ concentration that is equal $0.1 \%$ of the capacity, and the temperature of $+20^{\circ} \mathrm{C}$. The air is fanned in accordance with given flow and types of air diffusers.

The final goal of mathematical modelling was the modification of a neutral current plane, which would become a place of the air intake within the regenerative ventilation system, used for air input in the office buildings. 'The neutral current plane' is a plane, where the air mobility is nearly a zero value, which was preceded by full air regeneration at decrease of $\mathrm{CO}_{2}$ concentration up to concentration within ideal air, i.e. the concentration of $\mathrm{CO}_{2}$ is decreased up to the required meaning and the air is saturated with oxygen up to $21 \%$. The modification of the "neutral current" surface allows calculating the exact capacity of the grass cover.

The initial parameters of the mathematical modelling were set as follows: temperature of the air that is fanned in a winter garden premises through the diffusers; a standardized air temperature within the capacity of a winter garden; the geometrical parameters of a winter garden; the temperature of soil and walking paths; the concentration of $\mathrm{CO}_{2}$ in the air fanned inside winter garden from the office building; the initial air velocity fanned inside winter garden; the surface temperature of heating devices; the intensity of photosynthesis, taken in relation.

\section{Results and discussion}

In order to define air permeability of the greenery cover, it was decided to conduct a model, which would demonstrate the attenuation of air mobility once it permeates through the greenery cover at initially set meanings of air mobility.

Figure 4 shows the change of air mobility in relation to the height of the plant cover, with the initial meanings of air mobility being set. It is thus quite clear that once the air permeates through the greenery covers, its mobility equals zero. Naturally, the air mobility subsides inside the cover and reiterates the dependency of the air mobility taken before the cover.

The calculated values are used for the modelling of air regime of the winter garden, using the ANSYS-CFX software.

It should be mentioned, that the current issue was solved via analytically approximate methods, when the 


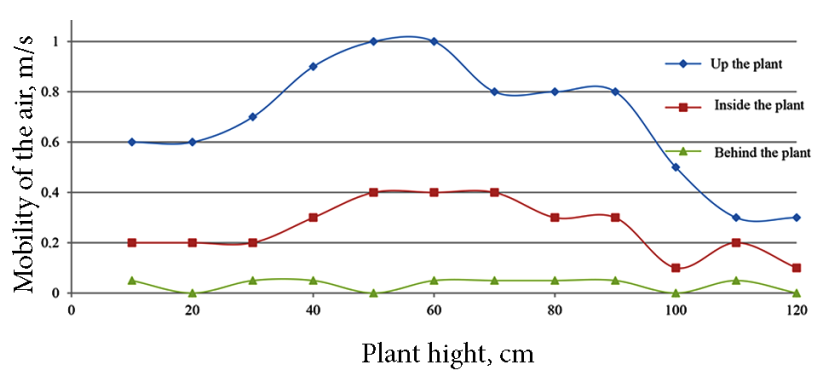

Figure 4 . The modification of air mobility within the capacity of the plant cover

air mobility before the process of permeability through the covers had been set analytically, and could have been changed by the sine law.

It was adhered to the Navier-Stokes equation at set meanings of viscosity and porosity of medium that imitates the cover. The relation of the air mobility within and without the cover appeared to be analogous to the one measured empirically.

The analysis of Figure 4 presented the resistance of airtightness of the plant covers within a winter garden. The difference between dynamic pressure before and after the plant masses: $\Delta P=0.6-0.0015=0.5985 \mathrm{~Pa}$; the volume airflow rate is $L=F \times v=1.8 \times 1 \times 1 \times 3600=6480 \mathrm{~m}^{3} / \mathrm{h}$; the mass airflow rate is $G=7776 \mathrm{~kg} / \mathrm{h}$.

$$
R u=\frac{|\Delta P|^{0.5}}{G} \times F .
$$

Now, having substituted for the given values in the formula, we would get $R u=0.0000995\left(\mathrm{~Pa}^{0,5} \times \mathrm{h} \times \mathrm{m}^{2}\right) / \mathrm{kg}$. Hence, the plant cover is a resistance plane under air permeability, thus the air mobility vanishes over a certain interval.

Based on the obtained results, it might be concluded that the air mobility attenuates almost entirely during the process of permeability through the plant cover, which might be seen as a positive outcome, since it contributes to the specification of thickness of the cover.

The Figures 5-7 demonstrate the diagrammed distributions of velocities using the chosen software, as well as temperatures and concentrations of $\mathrm{CO}_{2}$ within the capacity of winter garden. The aforementioned parameters show the behaviour of air quality under desired initial and boundary conditions within mathematical modelling.

It is worth mentioning that the process of the $\mathrm{CO}_{2}$ absorption by plant cover was calculated analytically as well. The mathematical problem definition is analogous to Stefan-Boltzmann's law. In this case, moving boundary is the boundary between two regions: partially purified and not purified from the carbon dioxide. The analytical solution allowed calculating the width of the green area required for the air cleaning from the carbon dioxide under specified distribution of flow rate, which is essentially important for a further execution of engineering calculations.

Based on the results acquired from the processes of modelling and approximation formulas, it might be concluded that the neutral current plane, (i.e. the distance from the soil, where the flowrate vanishes and the concentration of $\mathrm{CO}_{2}$ is deduced at minimum value), is the height that is equal $1.5-2 \mathrm{~m}$. This height exists within set geometrical parameters of the winter garden, parameters of indoor climate, incoming air consumption, deaerating, air consumption in the convective streams from the surface of the soil, leaves and heating systems, as well as the incoming air moving top-down.

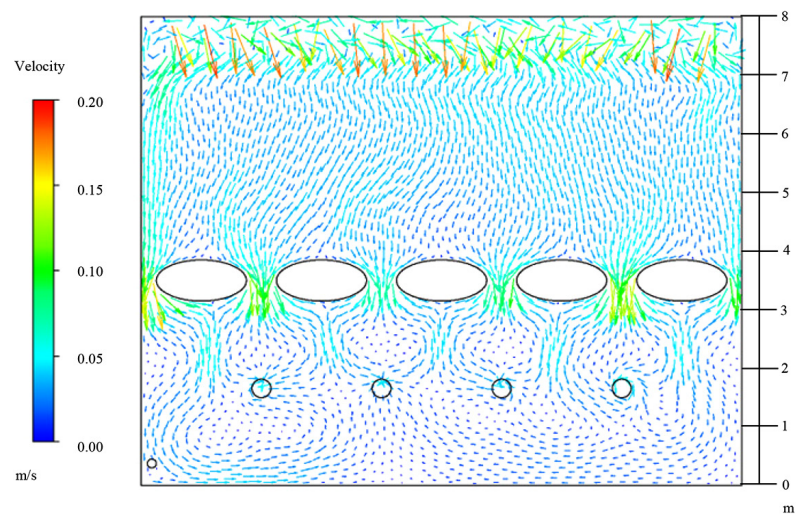

Figure 5. The vector diagram demonstrating the distribution of air velocity within the capacity of a winter garden

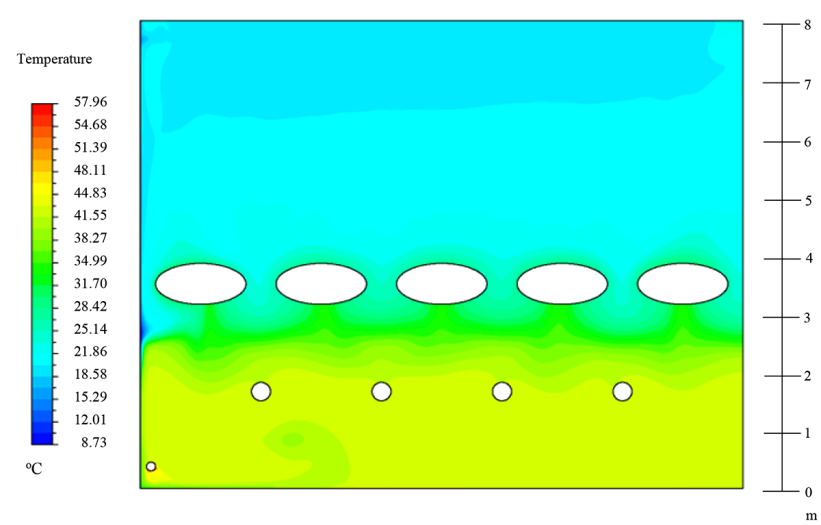

Figure 6. The diagram of distribution of temperature within the capacity of winter garden

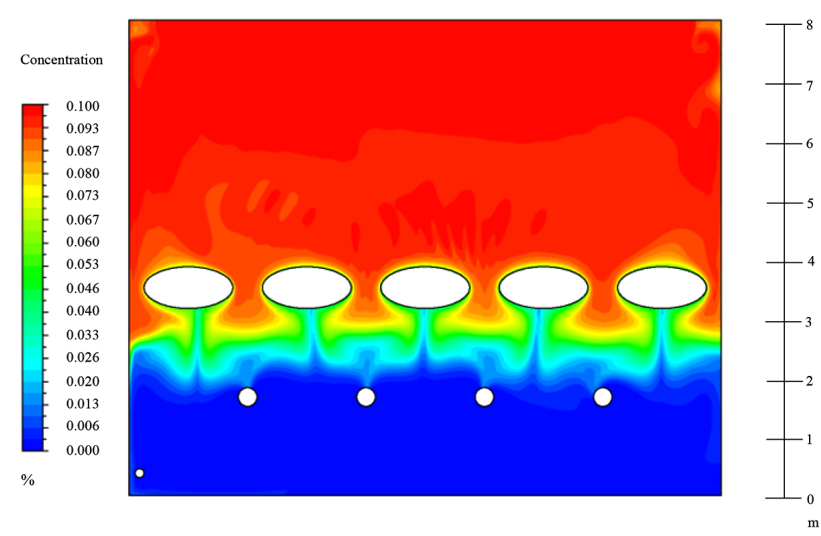

Figure 7. The diagram of distribution of the $\mathrm{CO}_{2}$ concentration within the capacity of winter garden 
The current plane completes the process of regeneration of the fanned air from the office buildings to the premises of the winter garden. Moreover, the given plane might be seen as the most advantageous for the organization of intake of the regenerated air, which is then fanned in the office premises. Within the air intake plane, the air could be described in terms of concentration of $\mathrm{CO}_{2}$ that vanishes or equals the concentration of $\mathrm{CO}_{2}$ within the ideal air, i.e. the air, which includes: $($ nitrogen $)=78.08 \%$, $($ oxygen $)=20.95 \%,($ argon $)=0.93 \%,($ carbon dioxide $)=$ $0.03 \%$, (helium, neon, krypton, xenon, ozone, radon, hydrogen, hydrogen peroxide, ammonia, iodine) $=0.01 \%$. This air is ideal for a healthy breathing. The features of such air ensure maximum saturation of blood at normal barometric pressure.

The changes in temperature, air mobility and concentration of $\mathrm{CO}_{2}$ were gathered from the calculations of the winter garden at its height, as shown in Figures 8-9.

The dark reaction of photosynthesis and respiration are biochemical processes, whereby the intensity is primarily defined by temperature and concentration of $\mathrm{CO}_{2}$. The immediate effect of temperature upon the intensity of metabolism modifies the speed of chemical reaction and enzyme activity. The congenial temperature interval depends on illumination and concentration of $\mathrm{CO}_{2}$. If the concentration of $\mathrm{CO}_{2}$ in the ambient air around plants is equal to the concentration in the open air $(0.03 \%)$, the optimum temperature is between $20-30{ }^{\circ} \mathrm{C}$. With an increase in concentration by $0,01 \%$, the optimum temperature increases its value by about $5{ }^{\circ} \mathrm{C}$. The rate or intensity

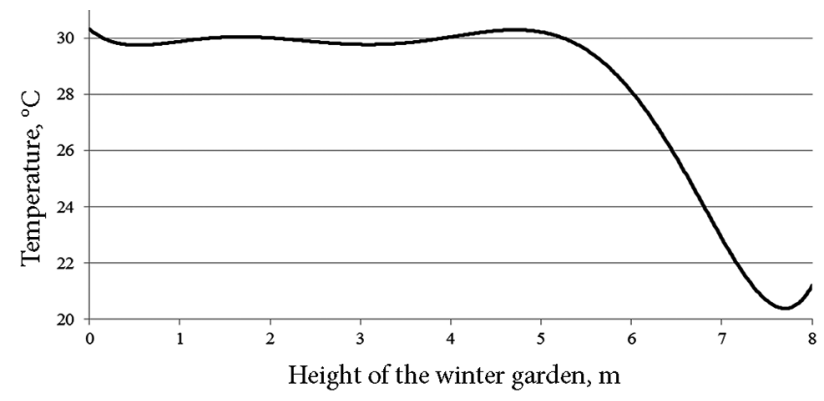

Figure 8. Modification of temperature at the height of a winter garden

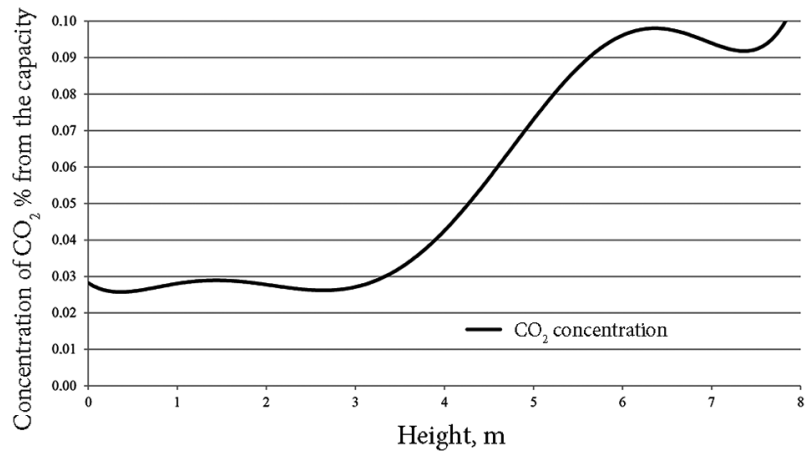

Figure 9. Modification of the concentration of $\mathrm{CO}_{2}$ at the height of a winter garden of photosynthesis is characterized by the amount of $\mathrm{CO}_{2}$ absorbed by a leaf surface unit $\left(\mathrm{dm}^{2}\right)$ per time unit $(\mathrm{h})$.

The main dependencies demonstrate that when the air is fanned in the capacity of the winter garden from the office premises, its temperature varies at the height of the building and, thus, equalizes by adjusting to the required temperature (Figure 8). At the same time, the concentration of $\mathrm{CO}_{2}$ in the air that moves from the office premises through the winter garden, decreases and becomes equal to concentration of an ideally configured air mass.

The mathematical modelling of winter garden premises along with the qualitative and quantitative parameters of modification at the height of the building's aerial mobility, temperature and concentration of $\mathrm{CO}_{2}$ was conducted via the ANSYS-CFX software. It allowed obtaining the locus of "neutral current planes" for air intake after the regeneration, so that the air could be fanned inside the office premises. It should be observed that the given dependencies are preserved even if the geometrical parameters (e.g. the height of the building) are to be changed. To average the dependencies obtained, it could be assumed that there may be simple analytical expressions, which are used for the calculations of the plants' mass.

\section{Conclusions}

1. The calculations, which were obtained via approximate analytical methods, confirm the accuracy of the chosen method that solves the present issue in full.

2. A recirculating regenerative scheme of the ventilation system within the office premises with the winter garden was developed. This scheme enables to decrease the concentration of $\mathrm{CO}_{2}$ and to increase the concentration of $\mathrm{O}_{2}$ in the capacity of the office premises since the air could recirculate through the building of the winter garden, which is the main difference from the schemes of the present ventilation systems of other office premises.

3. The obtained plane of the neutral current within the capacity of winter garden allowed calculating the distance from the soil of a winter garden (1.5-2 m), required for the organization of the air intake so that the air could be fanned inside the office premises. The result analysis of gas, humidity, air and thermal conditions allows discovering the behavior of the mass concentration of carbon dioxide, temperature and air speed on the height of the winter garden. This layout of neutral plane, in which the combination of the microclimate and the parameters of the gas regime is ideal for the regenerative air delivery into the office premises.

4. The proposed methodology based on the ANSYSCFX software, ensures a successful calculations of heating and aerial regimes within buildings that might differ in accordance with various engineering practices. A mathematical model, targeted at the 
analysis of the dynamics related to gas and thermal modes in the winter garden and the office premises, was developed. This model allows implementing a recirculating-regenerative air ventilation system along with the climate change and internal air gas composition control.

5. The analytical solution proposed for the process of the $\mathrm{CO}_{2}$ absorption by plant calculation allowed calculating the width of the green area required for the air cleaning from the carbon dioxide under specified distribution of flow rate, which is essentially important for a further execution of engineering calculations.

6. The full-scaled study results of microclimate parameters and gas composition in the air of office premises and winter garden are comparable with the calculations by specifically developed software. These results confirm adequacy of a mathematical model of the dynamic mass and heat changing systems. If the recirculating-regenerative ventilation systems operate properly, the discrepancy does not exceed $15 \%$.

\section{References}

Allen, J. G.; MacNaughton, P.; Satish, U.; Santanam, S.; Vallarino, J.; Spengler, J. D. 2016. Associations of cognitive function scores with carbon dioxide, ventilation, and volatile organic compound exposures in office workers: a controlled exposure study of green and conventional office environments, Environmental Health Perspectives 124(6): 805-812.

Alonso, M. J.; Mathisen, H. M.; Collins, R. 2015. Ventilative cooling as a solution for highly insulated buildings in cold climate, Energy Procedia 78: 3013-3018. https://doi.org/10.1016/j.egypro.2015.11.707

Chenari, B., Carrilho, J. D., Gameiro, M. 2016. Towards sustainable, energy-efficient and healthy ventilation strategies in buildings: a review, Renewable and Sustainable Energy Reviews 59: 1426-1447. https://doi.org/10.1016/j.rser.2016.01.074

Enteria, N.; Yoshino, H.; Satake, A.; Takaki, R.; Ishihara, H.; Baba, S. 2016. Benefits of utilizing on-site and off-site renewable energy sources for the single family detached house, International Journal of Energy and Environmental Engineering 7(2): 145-166. https://doi.org/10.1007/s40095-016-0205-5

Gallego, E.; Roca, F. J.; Perales, J. F.; Guardino, X. 2013. Experimental evaluation of VOC removal efficiency of a coconut shell activated carbon filter for indoor air quality enhancement, Building and Environment 67: 14-25. https://doi.org/10.1016/j.buildenv.2013.05.003

Germanova, T. V.; Kernozhitskaya, A. F. 2014. Zagryaznenie atmosfernogo vozduha goroda avtomobilnim transportom, Sovremennye naukoyemkie technologii (2): 26-29 (in Russian). Available from Internet: http://cyberleninka.ru/article/n/za- gryaznenie-atmosfernogo-vozduha-goroda-avtomobilnymtransportom-na-primere-tyumeni

Gershuni, G. Z.; Zhuchovickiy, E. M. 1989. Ustoichivost Konvektivnyh Techeniy. Nauka (in Russian).

Hyttinen, M.; Pasanen, P.; Björkroth, M.; Kalliokoski, P. 2007. Odors and volatile organic compounds released from ventilation filters, Atmospheric Environment 41(19): 4029-4039. https://doi.org/10.1016/j.atmosenv.2007.01.029

Kim, M. K.; Baldini, L.; Leibundgut, H.; Wurzbacher, J. A.; Piatkowski, N. 2015. A novel ventilation strategy with CO2 capture device and energy saving in buildings, Energy and Buildings 87: 134-141. https://doi.org/10.1016/j.enbuild.2014.11.017

Kvashnin, I. M.; Gurin, I. I. 2008. K voprosu o normirovanii vozduhoobmena po soderzhaniyu $\mathrm{CO} 2 \mathrm{v}$ naruzhnom I vnutrennem vozduhe, $A V O K 5$ (in Russian).

Leivo, V.; Turunen, M.; Aaltonen, A.; Kiviste, M.; Du, L.; Haverinen-Shaughnessy, U. 2016. Impacts of Energy Retrofits on Ventilation Rates, CO2-levels and Occupants' Satisfaction with Indoor Air Quality, Energy Procedia 96: 260-265. https://doi.org/10.1016/j.egypro.2016.09.148

Lott, M. C.; Pye, S.; Dodds, P. E. 2017. Quantifying the co-impacts of energy sector decarbonisation on outdoor air pollution in the United Kingdom, Energy Policy 101: 42-51. https://doi.org/10.1016/j.enpol.2016.11.028

Paevere, P.; Brown, S.; Brown, S. 2008. Project: Regenerating Construction to Enhance Sustainability Task 3: Occupant Health, Wellbeing and Productivity.

Raji, B., Tenpierik, M. J., Dobbelsteen, A. Van Den. 2015. The impact of greening systems on building energy performance: a literature review, Renewable and Sustainable Energy Reviews 45: 610-623. https://doi.org/10.1016/j.rser.2015.02.011

Rymarov, A. G.; Savichev, V. V. 2013. Osobennosti raboty regenerativnoi sistemy ventilyacii administrativnogo zdaniya s zimnim sadom, Vestnik MGSU (3): 174-177 (in Russian).

Sinitsyn, V. I.; Shurshakova, E. V. 2015. Sovremennye tendencii v proektirovanii system teplogazosnabzheniya i ventilyacii. Ekologiya i stroitelstvo (4): 15-17 (in Russian). Available from Internet: http://cyberleninka.ru/article/n/sovremennyetendentsii-v-proektirovanii-sistem-teplogazosnabzheniya-iventilyatsii

Steinemann, A.; Wargocki, P.; Rismanchi, B. 2017. Ten questions concerning green buildings and indoor air quality, Building and Environment 112: 351-358. https://doi.org/10.1016/j.buildenv.2016.11.010

Toledo, L.; Cropper, P. C.; Wright, A. J., 2016. Unintended consequences of sustainable architecture: evaluating overheating risks in new dwellings, in 32th International Conference on Passive and Low Energy Architecture. Cities, Buildings, People: Towards Regenerative Environments, 15-16 July 2016, Los Angeles, United States of America.

Wargocki, P.; Wyon, D. P. 2017. Ten questions concerning thermal and indoor air quality effects on the performance of office work and schoolwork, Building and Environment 112: 359-366. https://doi.org/10.1016/j.buildenv.2016.11.020 